\title{
Anatomía microscópica de las glándulas paratiroides normal. Principios generales para residentes de endocrinología y patología, con una breve nota histórica
}

\section{Microscopic anatomy of the parathyroid gland. General principles for endocrinology and pathology residents, with a brief historical note}

\author{
Pablo José ERRÁez-Jaramilio ${ }^{1}$ y Carlos OrTiz-Hidalgo ${ }^{1,2 *}$
}

${ }^{1}$ Departamento de Anatomía Patológica, Hospital y Fundación Médica Sur; ${ }^{2}$ Departamento de Biología Celular y Tisular, Escuela de Medicina, Universidad Panamericana. Ciudad de México, México

\section{RESUMEN}

\begin{abstract}
Su tamaño relativamente pequeño y su localización intratiroidea son lo que probablemente explica el hallazgo tardío de las glándulas paratiroides y la posterior identificación de sus funciones fisiológicas. Las glándulas paratiroides fueron el último órgano reconocido en el hombre, y fueron descubiertas en 1855 por Owen en Inglaterra y en 1880 por Sandström en Suecia. Las cuatro glándulas paratiroides normales derivan de las bolsas faríngeas; las glándulas superiores de la cuarta bolsa y las inferiores de la tercera bolsa. Normalmente, el $80-97 \%$ de los adultos tienen cuatro glándulas, pero el $5 \%$ tiene menos de cuatro y entre el 3-13\% tiene glándulas supernumerarias. Cada glándula mide $3-7 \mathrm{~mm}$ y pesa $30-40 \mathrm{mg}$ y una glándula normal no excede de $70 \mathrm{mg}$. Hay dos tipos de células parenquimatosas: las células principales son las predominantes y tienen organelos similares a los que se encuentran en otros tejidos endocrinos, y las células oxífilas, que por microscopia electrónica se caracterizan por la presencia de abundantes mitocondrias. La comprensión integral de la anatomía microscópica y la embriología de las glándulas paratiroides es un requisito para el manejo clínico y quirúrgico exitoso de la enfermedad paratiroidea.
\end{abstract}

Palabras clave: Paratiroides. Histología. Inmunohistoquímica.

\begin{abstract}
Their relatively small size and intrathyroidal localization likely account for the belated recognition of the parathyroid glands and the even later identification of their physiological functions. The parathyroid glands were the last organ to be recognized in man, and were discovered in 1855 by Owen in England and in 1880 by Sandström in Sweden. The normal four parathyroid glands are derived from the pharyngeal pouches, the upper glands from the fourth pouch and the lower glands from the third pouch. Normally $80-97 \%$ of adults have four glands, but $5 \%$ have fewer than four, and $3-13 \%$ have supernumerary glands. Each gland usually measures 3-7 $\mathrm{mm}$ and weights $30-40 \mathrm{mg}$ each, with the largest normal gland not exceeding $70 \mathrm{mg}$. There are two parenchymal cell types: the predominant chief cells that have organelles similar to those found in other endocrine tissues, and the oxyphil cells, that ultrastructurally are characterized by the presence of closely packed mitochondria. A comprehensive understanding of the microscopical anatomy and embryology of the parathyroid glands is a requisite to the successful clinical and surgical management of parathyroid disease conditions.
\end{abstract}

Key words: Parathyroid gland. Histology. Immunohistochemistry.
Correspondencia:

*Carlos Ortiz-Hidalgo

E-mail: ortizhidalgocarlos@gmail.com
Fecha de recepción: 16-10-2019

Fecha de aceptación: 30-12-2019

DOI: 10.24875/RME.19001955
Disponible en internet: 25-02-2020

Rev Mex Endocrinol Metab Nutr. 2020;7:43-53

2462-4144 / ๑ 2019 Sociedad Mexicana de Nutricion y Endocrinologia, AC. Publicado por Permanyer. Este es un artículo open access bajo la licencia CC BY-NC-ND (http://creativecommons.org/licenses/by-nc-nd/4.0/). 
INTRODUCCIÓN CON UNA BREVE NOTA HISTÓRICA

Las paratiroides son glándulas endocrinas que se encuentran adosadas a la parte posterior de los polos superiores e inferiores de los lóbulos tiroideos ${ }^{1,2}$. La principal función de estas glándulas es la secreción de hormona paratiroidea (HPT), que junto con el 1-25 dihidroxicolecalciferol $(1,25-(\mathrm{OH}) 2 \mathrm{D} 3$, metabolito activo de la vitamina D) y la calcitonina integran un complejo sistema endocrino que controla la homeostasis del calcio $\left(\mathrm{Ca}^{2+}\right)$ y del fósforo (P). El tamaño relativamente pequeño de estas glándulas y su localización intratiroidea fueron posiblemente la razón de su descubrimiento tardío y la posterior descripción de sus propiedades fisiológicas ${ }^{2,3}$.

Se ha sugerido que las glándulas paratiroides aparecieron hace aproximadamente 100 millones de años, en el contexto del desarrollo evolutivo de los anfibios ${ }^{4}$. La aparición de las glándulas coincidió con la transición del medio marino rico en $\mathrm{Ca}^{2+}$ al ambiente terrestre. Sin embargo, hay autores que han sugerido que esto tuvo lugar hace $360-286$ millones de años, durante el periodo carbonífero de la era paleozoica ${ }^{4}$. Se le atribuye al anatomista inglés Sir Richard Owen (1804-1892), originario de Lancaster (Inglaterra), la primera descripción de estas glándulas, cuando realizó la autopsia de un rinoceronte que había muerto en el zoológico de Londres en $1849^{5,6}$ (Fig. 1). Owen presentó el resultado de la autopsia ante la Sociedad Zoológica de Londres el 12 de febrero de 1850 y en el apartado del informe titulado «Víscera torácica» describió a la paratiroides como: "a small compact yellow glandular body attached to the thyroid gland at the point where the veins emerge» (un pequeño cuerpo compacto glandular amarillo adosado a la tiroides en el punto donde emergen las venas) ${ }^{7,8}$. Owen no dio nombre ni propuso función alguna a estas glándulas. El espécimen que muestra la glándula paratiroide de la laringe y la tráquea del rinoceronte se encuentra en exhibición en el Museo Hunteriano de The Royal College of Surgeons of England (Londres, Inglaterra). Tres años después de la publicación de Owen, el histólogo polaco Robert Remak (1815-1865), y posteriormente en 1863 el patólogo alemán Rudolf
Virchow (1821-1902), describieron glándulas similares en gatos y humanos ${ }^{7,8}$. Y fue en 1877 cuando se realizó la primera descripción anatómica e histológica de estas glándulas a cargo del entonces estudiante de medicina Ivar Viktor Sandström (18521889), durante la disección del cuello de un perro, en la Universidad de Uppsala en Suecia ${ }^{9}$. Sandström publicó en 1880 en la revista Upsala Läkareförenings förhandlingar su trabajo titulado Om en ny körtel hos menniskan och atskilliga däggdjur (Sobre una nueva glándula en el hombre y varios mamíferos); llamó a estas estructuras glandulae parathyroidea y sugirió que eran porciones embrionarias no desarrolladas de la glándula tiroides. Sandström tradujo su manuscrito al alemán, con la esperanza de publicarlo en la revista que editaba Rudolf Virchow, pero este no lo aceptó, supuestamente debido a la longitud del artículo, que constaba de 30 páginas ${ }^{10}$. Hay historiadores que creen que la verdad es que cuando Virchow leyó el manuscrito se dio cuenta de que era la glándula paratiroides que él también había observado en gatos y humanos, y posiblemente no quiso darle el crédito al joven sueco por el descubrimiento de estas nuevas glándulas ${ }^{11}$.

Casi una década después de la publicación de Sandström, el fisiólogo y endocrinólogo francés Marcel Eugène Émile Gley (1857-1930) descubrió la importancia funcional de estas glándulas cuando observó que durante experimentos realizados en perros, estos presentaban tetania después de la destrucción inadvertida de las paratiroides durante la extirpación tiroidea ${ }^{12,13}$. Una década después de los estudios de Gley, el gran patólogo austriaco y profesor de la Universidad de Viena Jacob Erdheim (1874-1937) corroboró los hallazgos de Gley por medio de una investigación que involucró el examen del tejido en el cuello de animales que habían desarrollado tetania ${ }^{14}$. Erdheim observó también que no había tejido paratiroideo en las personas que habían muerto por tetania después de cirugía tiroidea, por lo que concluyó que la causa de la tetania era la pérdida del tejido paratiroideo ${ }^{15}$.

La relación que tiene las paratiroides con la enfermedad ósea fue originalmente descrita por el patólogo alemán Friedrich Daniel von Recklinghausen (18331910), cuando informó el estudio de 16 pacientes en quienes los huesos habían sido reemplazados por 


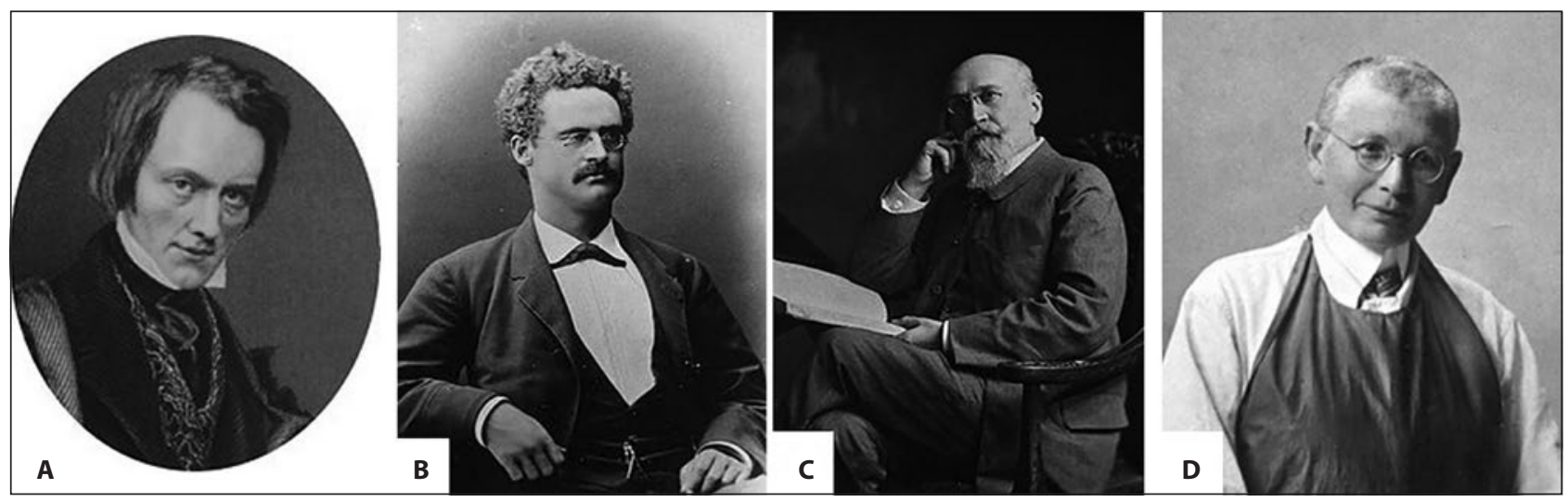

Figura 1. Pioneros en el descubrimiento y función de las glándulas paratiroides. A: Richard Owen. B: Ivar Viktor Sandström. C: Marcel Eugène Émile Gley. D: Jakop Erdheim.

fibrosis y quistes, a lo que llamó osteítis fibrosa quística (hoy conocida como enfermedad de von Recklinhausen del hueso; no confundirla con la enfermedad de von Recklinghausen neurofibromatosis tipo I) ${ }^{16}$. La relación que tienen estas glándulas con alteraciones óseas fue confirmada por el patólogo de la Universidad de Viena Jacob Erdheim (1874-1937) (también conocido por la descripción de la enfermedad de Erdheim-Chester), quien pudo demostrar que la presencia de las glándulas paratiroides era necesaria para el buen crecimiento óseo y dental en ratas, y posteriormente informó que las cuatro glándulas paratiroides estaban crecidas en pacientes con osteomalacia y raquitismo, por lo que dedujo que se trataba de una hiperplasia compensatoria ${ }^{13}$.

La HPT fue aislada por dos investigadores independientes. En 1923, Adolph Melanchthon Hanson (1880-1959) cuando era estudiante de medicina de la Universidad de Minnesota, desarrolló un método para extraer la HPT de las glándulas paratiroides bovinas para el tratamiento de la tetania, en un laboratorio acondicionado en su casa en Fauribault, Minnesota ${ }^{17,18}$. Por separado, el bioquímico canadiense de la Universidad de Alberta James Bertram Collip (1892-1965) estaba convencido de que las glándulas paratiroides contenían una hormona reguladora del $\mathrm{Ca}^{2+}$ y publicó sus resultados del aislamiento de la HPT en 1925, y llamó a esta hormona parathyrin ${ }^{19}$. Collip es mejor recordado por su papel en el descubrimiento de la insulina (aunque el comité del Premio Nobel no lo consideró para de ese premio) que por su papel en el descubrimiento de la HPT, una proeza igualmente importante ${ }^{19}$. El método utilizado por ambos fue similar; lo que hicieron fue triturar las glándulas paratiroides de un buey y estas fueron tratadas con ácido clorhídrico diluido, que luego se concentró por vaporación y tituladas a un $\mathrm{pH}$ neutro ${ }^{18}$. Finalmente, Solomon A. Berson (1919-1972) y Rosalyn S. Yalow (1921-2011) desarrollaron en 1963 un inmunoensayo para la medición de la HPT, lo que le valió a Yalow el Premio Nobel en Medicina o Fisiología en 1977 (Berson no recibió el premio debido a que había muerto de un infarto al corazón a la prematura edad de 53 años en 1972, y no se otorgan premios Nobel póstumos) ${ }^{20}$.

Fuller Albright (1900-1969) debe de ser mencionado en los conceptos actuales en fisiología de las glándulas paratiroides. Albright fue alumno de Erdheim mientras era estudiante de cuarto año de medicina en Harvard (en 1923), quien inició su afición por estas glándulas. Desde ese año en que presentó el trabajo titulado The physiology and physiological pathology of calcium, y hasta su muerte en 1969, dedicó toda su carrera al estudio de las paratiroides ${ }^{13,21}$.

\section{EMBRIOLOGÍA DE LAS GLÁNDULAS PARATIROIDES}

Las glándulas paratiroides se originan a partir del endodermo de la tercera y cuarta bolsas faríngeas, 


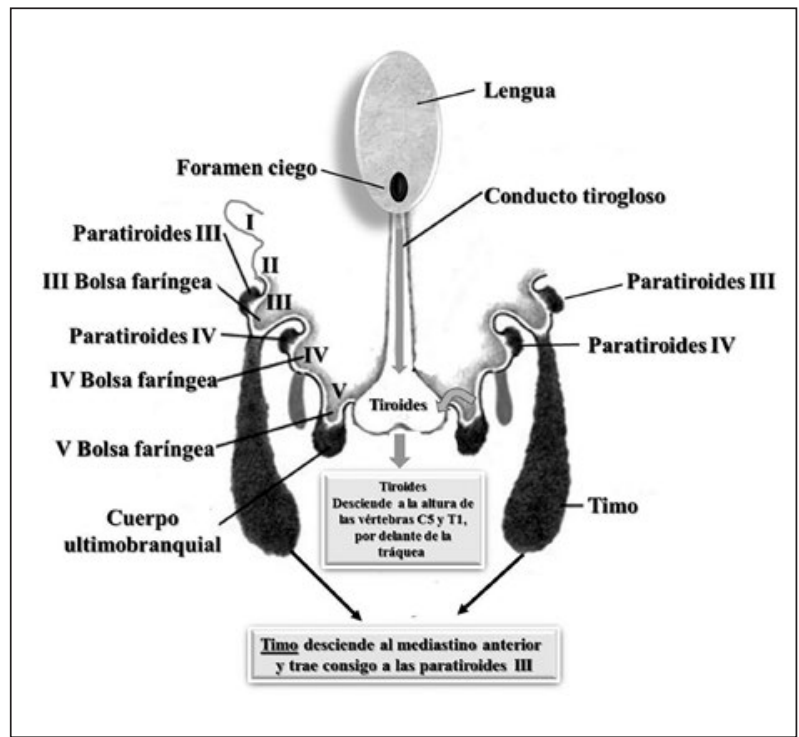

Figura 2. Esquema de la embriología de la faringe primitiva de un embrión de 8-10 semanas (adaptada de Scharpf, et al.24).

entre las semanas 5 y 6 de la gestación, cuando el embrión mide $9 \mathrm{~mm}^{22}$ (Fig. 2). El desarrollo de la paratiroides está regulado por varios genes que codifican diferentes factores de transcripción ${ }^{23}$. Las glándulas inferiores proceden del ala dorsal de la tercera bolsa faríngea junto con el timo (ala ventral), mientras que las glándulas superiores surgen a partir de la cuarta bolsa faríngea. Por esta relación embriológica, a las paratiroides inferiores se han referido como paratiroides III y a las superiores como paratiroides IV. De estos sitios migran en dirección caudal y medial, hasta llegar a su posición final detrás de la glándula tiroides, hacia la séptima semana de vida intrauterina ${ }^{24}$. El timo se origina de la tercera bola faríngea, y migra hacia abajo arrastrando las glándulas inferiores y las deposita en la parte inferior/posterior de la tiroides, mientras que el par de glándulas superiores migran hacia la porción superior posterior de la tiroides ${ }^{25}$. Dado que el destino final del timo está en el mediastino, en ocasiones es posible encontrar paratiroides ectópicas derivados de la tercera bolsa faríngea dentro de la cavidad torácica asociadas al timo, cuando estas no se desprenden en el cuello ${ }^{26}$. Las paratiroides superiores, junto con los lóbulos laterales de la glándula tiroides, derivan de la parte caudal de la cuarta bolsa faríngea (cuerpo ultimobranquial o cuerpo posbranquial), por lo que también se las ha llamado «paratiroides tiroideas». Ambos forman un complejo bilobulado que se separa y finalmente la paratiroides superior adquiere su localización final de la parte posterior, a la altura de la unión cricotiroidea de la laringe junto a la intersección de nervio laríngeo recurrente y la arteria tiroidea inferior. Durante el desarrollo, porciones de las glándulas paratiroides se pueden dividir en dos, lo que explica la presencia ocasional de cinco glándulas. Las glándulas paratiroides ectópicas pueden encontrase en la vecindad de la glándula tiroides, dentro del parénquima tiroideo, en el surco traqueoesofágico y la región retroesofágica, dentro de la vaina de la arteria carótida, junto a la horquilla carotídea, en el ligamento tirotímico, en el mediastino anterior, en el pericardio, en el área de la ventana aortopulmonar, en el epineuro del nervio vago, en ganglios linfáticos cervicales y en la columna torácica ${ }^{26}$. Por lo anterior el nombre de glándulas paratiroides puede no ser exacto, pues no solo son "para», sino indistintamente pueden ser «epi», «intra» o «extra» tiroideas (Fig. 3).

\section{ANATOMÍA E HISTOLOGÍA}

Entre el 90 y el $97 \%$ de los seres humanos tienen cuatro glándulas paratiroides ubicadas en las posiciones superior e inferior izquierda y derecha de la glándula tiroides ${ }^{25,27}$. Aproximadamente entre el 2 y el $13 \%$ de individuos sanos presentan glándulas supernumerarias, entre el 1 y el 3\% de las personas tienen solo tres glándulas paratiroides y el $0.6 \%$ pueden tener hasta seis. Hay casos aislados informados con la presencia de 12 glándulas paratiroi$\operatorname{des}^{25,27}$. Las paratiroides superiores están en íntima relación con la parte posterior de la cápsula tiroi$\mathrm{dea}^{28}$. Las paratiroides inferiores tienen una localización más variable en los polos inferiores de la tiroides. La simetría como «imagen en espejo» se presenta en el $80 \%$ para las paratiroides superiores y el $70 \%$ para las inferiores, por lo que, durante la disección, al encontrar una glándula paratiroides se puede trazar una línea imaginaria hacia el lado puesto, lo que ayuda a encontrar la glándula contralateral. 


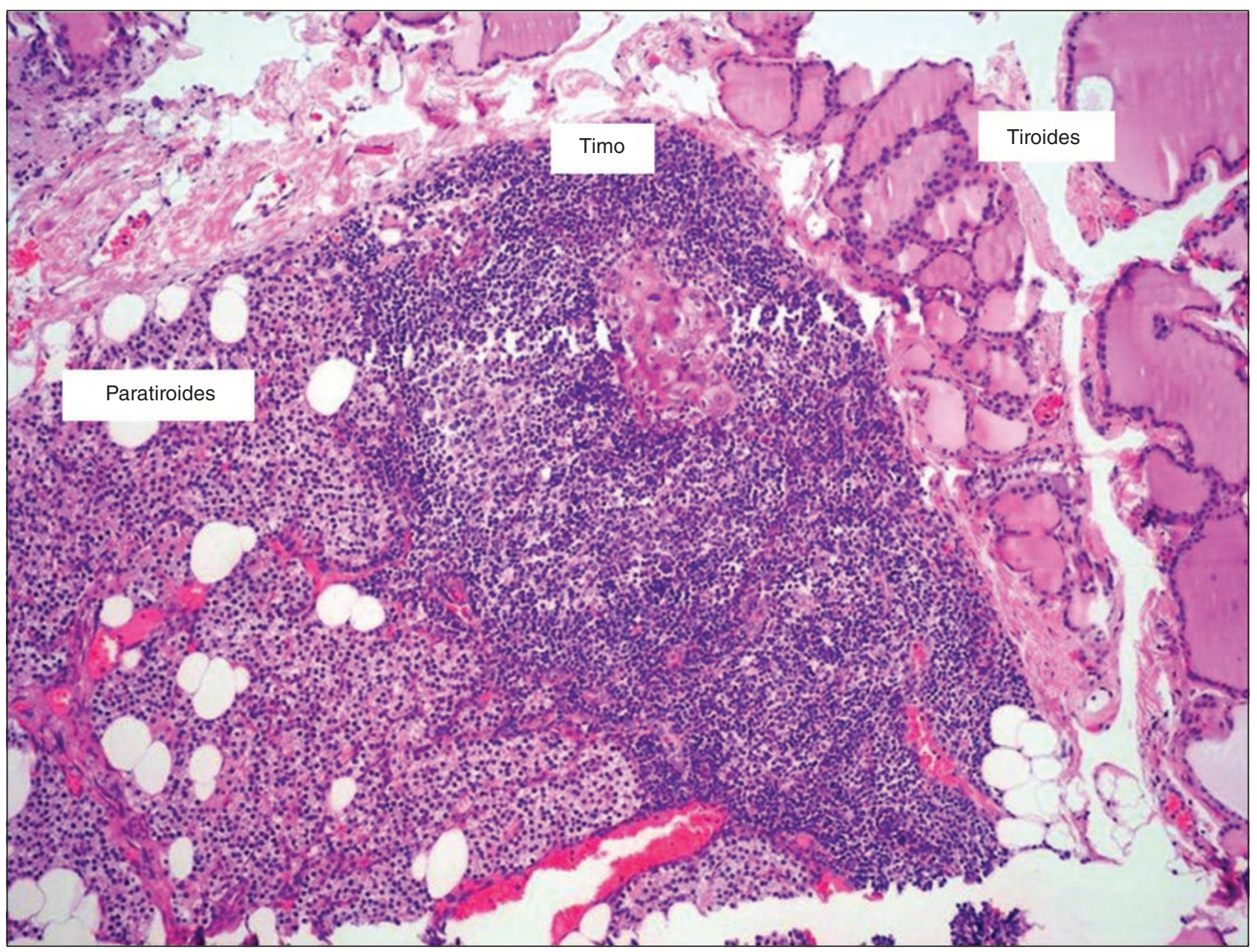

Figura 3. Fotomicrografía de un corte de glándulas tiroides donde se encontró una paratiroides intratiroidea (izquierda de la ilustración) con timo (centro de la ilustración). Lo anterior ilustra la relación entre tiroides, timo y paratiroides.

La irrigación proviene principalmente de la arteria tiroidea inferior, que es el suministro vascular primario tanto para las glándulas paratiroides superiores como inferiores en el $76-86 \%$ de los casos. Colateralmente reciben irrigación por parte de las arterias tiroideas superiores y las arterias laríngea, traqueal y esofágica. Las venas paratiroides drenan hacia el plexo tiroideo venoso, y la inervación, procedentes de las ramas tiroideas de los ganglios cervicales (simpáticos). Estos nervios son vasomotores (no secretomotores), y la secreción endocrina de la HPT se controla vía hormonalmente ${ }^{27}$.

Las glándulas paratiroides tienen forma elipsoidal, algo aplanadas, y son color marrón; sin embargo, con la edad adquieren un tono amarillento debido a que tienen cantidades mayores de tejido adiposo que en los adultos, que puede llegar a ser entre el 60 y el $70 \%$ del peso glandular. La cantidad de tejido adiposo suele ser mayor en mujeres que en hombres ${ }^{27-29}$. Cada glándula mide en promedio 5.0 $\times 3.0 \times 1.0 \mathrm{~mm}$, pero el tamaño puede variar de $3 \mathrm{a}$ $7 \mathrm{~mm}$. Las paratiroides inferiores suelen ser un poco más grandes que las superiores ${ }^{30}$. El peso de cada glándula varía de 30 a $40 \mathrm{mg}$, y de acuerdo a Saffos, et al., en un estudio realizado en 77 pacientes de más de 25 años, el peso promedio de una glándula normal es de $27.7 \mathrm{mg}$, pero puede alcanzar hasta 85 $\mathrm{mg}^{31,32}$. Sin embargo, para fines prácticos, cualquier glándula con un peso mayor de $60-70 \mathrm{mg}$ se considera patológica ${ }^{27-29}$. El peso combinado de las cuatro glándulas paratiroides en hombres adultos es de $120 \pm 3.5 \mathrm{mg}$ y en la mujer adulta de $142 \pm 5.2 \mathrm{mg}$. 


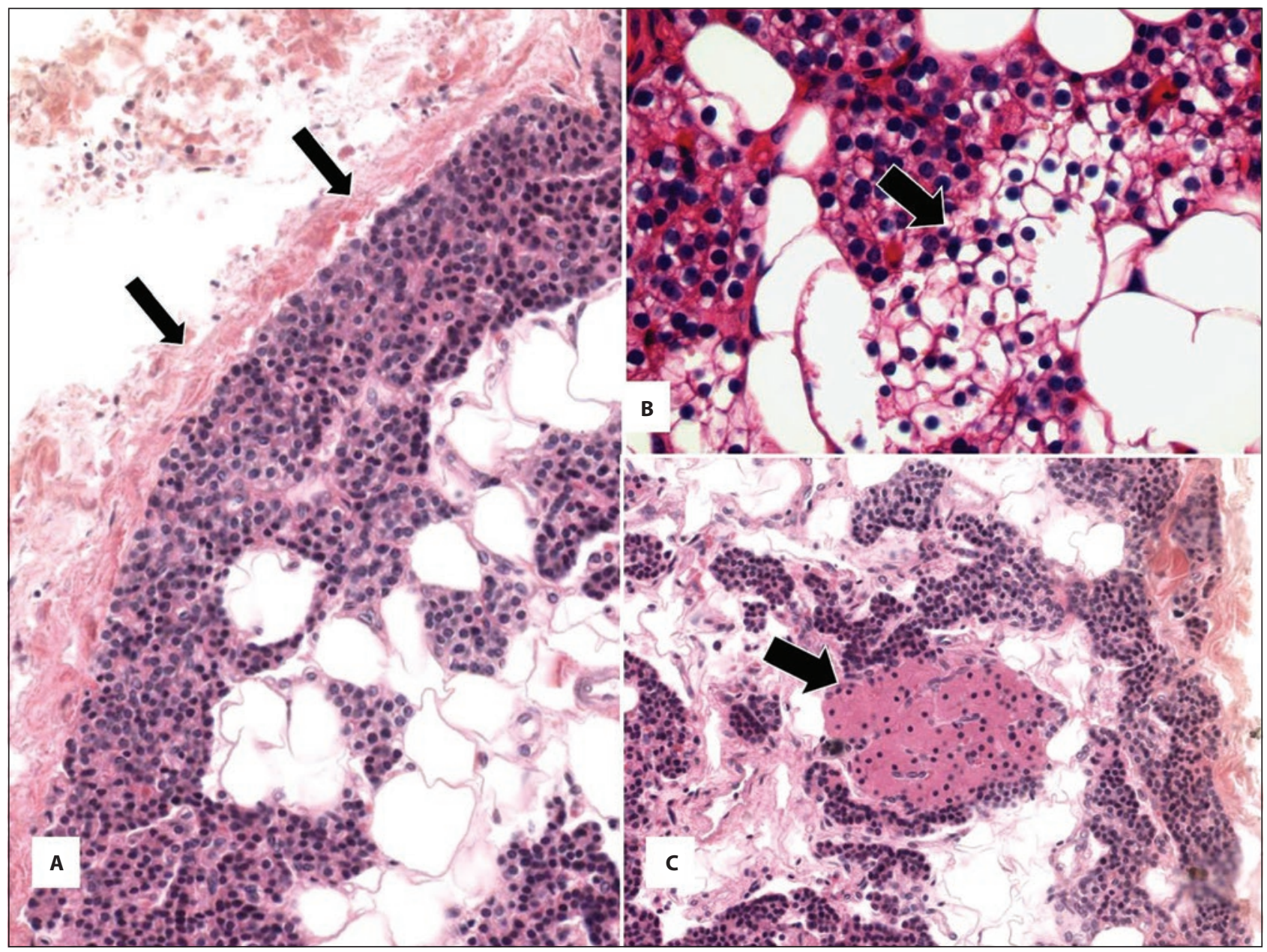

Figura 4. La glándula paratiroides muestra: que está recubierta por una cápsula de tejido fibroso (flechas) (A), células principales (las más abundantes) y células claras (flechas) (B) y células principales (las más abundantes con un grupo de células oxifílicas) (flechas) (C).

Existe una abundante red vascular pericapsular, por lo que las glándulas paratiroides sangran profusamente, dato que puede ser de utilidad para el cirujano para diferenciaras de tejido adiposo, ganglios linfáticos, timo o parénquima tiroideo, que no sangran en forma tan abundante cuando se $\operatorname{cortan}^{27}$.

Histológicamente las glándulas paratiroides están delimitadas por una delgada cápsula fibrosa vascularizada, pero de acuerdo a Saffos, et al., algunas paratiroides pueden carecer de cápsula31 (Fig. 4A). El parénquima está compuesto por células que se agrupan en cordones y nidos irregulares que ocasionalmente forman pseudofolículos, separadas por delicados tabiques de tejido conectivo rodeados de vasos capilares ${ }^{27-29}$. Hay dos tipos de células que corresponden a un mismo tipo celular en diversas fases fisiológicas: las células principales y las células oxifílicas (acidófilas) ${ }^{33}$ (Fig. 4B).

Las células principales son las más abundantes y las productoras de la HPT. Miden de 6 a $9 \mu \mathrm{m}$ de diámetro, son poliédricas, con núcleo central redondo o elíptico con uno o más nucléolos pequeños, citoplasma anfófilo (se tiñen igualmente por los colorantes básicos y ácidos) o levemente eosinófilo y por microscopia electrónica se aprecian algunas mitocondrias, abundante retículo endoplásmico rugoso, aparato de Golgi y numerosas vacuolas citoplásmicas de grasa. El contenido de grasa intracitoplásmica es inversamente proporcional a la actividad endocrina, es decir, un incremento de grasa citoplásmica corresponde a una glándula suprimida, mientras que una glándula hormonalmente activa, 
como en un adenoma o una hiperplasia que están en una fase activa de síntesis de HPT, tienen poca o nula grasa citoplásmica. De las células principales se identifican dos tipos; unas con citoplasma obscuro y otras con citoplasma claro (water clear cells), que constituye fases funcionales de la misma célula (Fig. 4B). Las células principales obscuras contienen lipofuscina y mayor cantidad de organelos, por lo que se consideran más activas, y las células claras son un poco más grandes (10-15 $\mu \mathrm{m})$, tienen glucógeno y lípidos en el citoplasma y representan hasta el $80 \%$ de las células en los adultos (Fig. 4C).

Las células oxifílicas, o acidófilas, representan el 3\% de las células paratiroideas y aparecen alrededor de los 7 años de edad ${ }^{27-29}$. Miden entre 12 y $20 \mu \mathrm{m}$ y se pueden encontrar asiladas o más frecuentemente formando grupos celulares. Tienen lipofuscina citoplásmica y característicamente numerosas mitocondrias, que son la causa de la acidofilia intensa característica de estas células. Las células oxifílicas se asemejan a las células de Hürtle de la tiroides, contienen muy poca HPT y cromogranina $A$, y no se conoce con exactitud su función, ni el porqué de su aparición a inicios de la adolescencia.

Existen pocas células de transición, que corresponden a una fase intermedia entre las células principales y las oxifílicas ${ }^{27,29,31}$.

\section{INMUNOHISTOQUÍMICA}

Característicamente las células principales y en menor proporción las células oxífílicas de la glándula paratiroides normal expresan parathormona en el citoplasma ${ }^{28}$ (Fig. 5). Además, hay expresión de parafibromina en el núcleo de las células principales, que es un dato importante para diferenciarlas por inmunohistoquímica de las células foliculares de la tiroides que son negativas a este marcador. La parafibromina es una proteína de 531 aminos codificada por el gen CDC73, también conocido como HRPT2 (hyperparathyroidism 2 gene), que está localizado en el brazo largo del cromosoma 1 en posición 31.2 (1q31.2) y funciona como supresor tumoral ${ }^{34}$. La parafibromina desempeña una función reguladora durante la proliferación celular, y la mutación de este gen conduce a la pérdida de la expresión de la proteína parafibromina, que trae como resultado la negatividad nuclear de este marcador por inmunohistoquímica. En el contexto clínico y patológico apropiado, la ausencia total de inmunomarcación de parafibromina en un tumor paratiroideo, junto con un índice de proliferación medido con Ki-67 mayor del $5 \%$, es diagnóstica de carcinoma paratiroideo $28,35,36$.

Las células de la glándula paratiroides expresan también los marcadores neuroendocrinos sinaptofisina y cromogranina A, así como CD56 y diversas queratinas (CK) como la queratina de amplio espectro OSCAR (CK 7, 8, 18 y19), el Cam5.3 (citoqueratina 8), la CK18 y la CK1924,25. Ninguno de estos últimos marcadores es específico para identificar las glándulas paratiroides ${ }^{28}$. El parénquima paratiroideo y los tumores originados de este pueden ser diferenciados de la tiroides adyacente por la negatividad a la tiroglobulina y TTF1 y por la positividad nuclear al GATA3 y al GCM2 (glial cell missing 2) que, este último, es un factor de transcripción, específico y sensible, asociado al desarrollo embriológico de la paratiroides ${ }^{28,37-39}$. Es de interés que se ha demostrado que los marcadores linfoides CD3, como el CD4, pueden ser positivos tanto en las glándulas paratiroides normales como en hiperplasias y adenomas, y hay informes de expresión focal de neurofilamentos y vimentina ${ }^{40}$.

\section{FUNCIÓN DE LAS GLÁNDULAS PARATIROIDES Y PRODUCCIÓN DE HORMONA PARATIROIDEA}

A pesar de que las glándulas paratiroides están localizadas dentro o cerca de la glándula tiroides, estas no tienen función alguna en común. Las paratiroides poseen un suministro vascular abundante, lo que es importante para el monitoreo adecuado del nivel de $\mathrm{Ca}^{2+}$ sérico ${ }^{2,41}$. Cuando la sangre pasa a través de las glándulas paratiroides, estas detectan la cantidad de $\mathrm{Ca}^{2+}$ presente y reaccionan produciendo mayor o menor cantidad de parathormona. Los gránulos citoplásmicos de las células principales contienen la HPT, también conocida como 


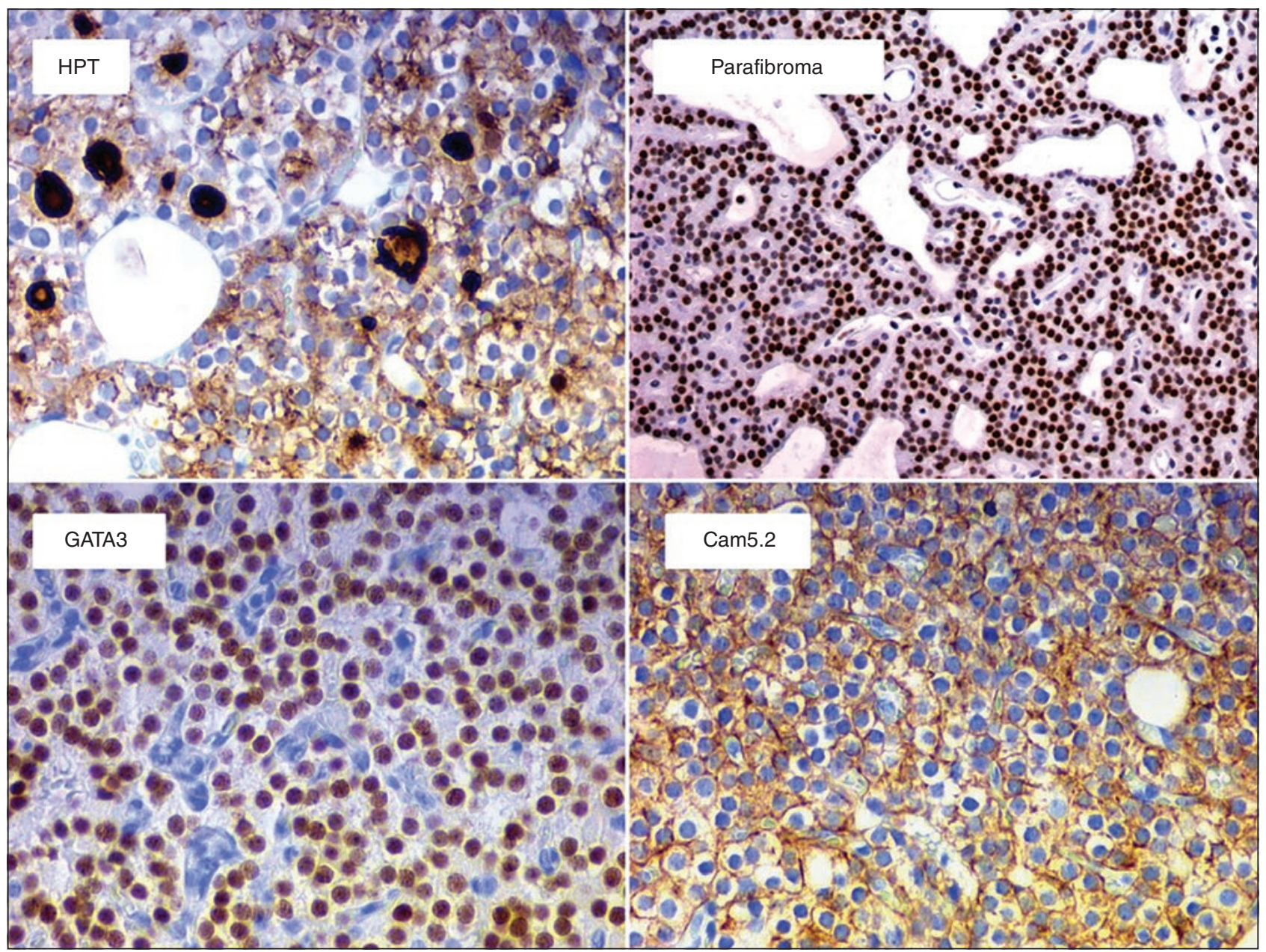

Figura 5. Inmunohistoquímica de las glándulas paratiroides. Característicamente expresan hormona paratiroidea (HPT) y parafibromina. Presentan también expresión de GATA3 y la queratina Cam5.2.

parathormona o paratirina, cuyo gen se encuentra localizado en el cromosoma 11 (11 p15.3/gen PTH1), y se secreta en respuesta a los niveles bajos de $\mathrm{Ca}^{2+}$. La HPT es sintetizada como un precursor polipeptídico de 115 aminoácidos llamado prepro-HPT. La conversión de prepro-HPT a pro-HPT ocurre durante el transporte de este polipéptido en las cisternas del retículo endoplásmico rugoso (donde se eliminan 25 aminoácidos), y en el aparato de Golgi se lleva a cabo la escisión de otro hexapéptido que permite la conversión a HPT madura/activa, que es un polipéptido de 84 aminoácidos de peso molecular de $9.4 \mathrm{kDa}^{42}$. En este punto, la HPT es «empaquetada» en vesículas secretoras y liberada cuando esta se requiera ${ }^{25}$. Toda la actividad biológica de la HPT reside en su dominio amino (NH2)-terminal, de tal forma que moléculas sintéticas compuestas de los residuos del NH2-terminal 34 (HPT [1-34]) pueden recapitular la actividad biológica de toda la molécula. El dominio terminal NH2 interactúa en el tejido blanco con el receptor de HPT tipo 1 (PTH1R), y este receptor transduce la señal de un relacionado genético de HPT, llamado proteína relacionada con la HPT (PTHrP); esta última está altamente expresada en huesos y riñones. La función de la HPT es la regulación de homeostasis extracelular de $\mathrm{Ca}^{2+} \mathrm{y}$ fosfato $\left(\mathrm{PO}_{4}{ }^{3-}\right)$. Una reducción de $\mathrm{Ca}^{2+}$ en el líquido extracelular y un aumento de $\mathrm{PO}_{4}{ }^{3-}$ estimulan la liberación de HPT en las glándulas paratiroides ${ }^{2,43,44}$. Las células principales (y en menor proporción la células oxifílicas) poseen en su membrana un sensor de $\mathrm{Ca}^{2+}$ (CaSR, calcium-sensing receptor) que es una 
proteína compleja con componentes extracelulares fijadores de $\mathrm{Ca}^{2+}$, siete componentes transmembrana y una porción intracelular que regula la síntesis de HPT a través de proteínas $G$ y fosfolipasa $C^{44}$. Cuando la calcemia disminuye (la concentración media de sérico de $\mathrm{Ca}^{2+}$ es de $9.5 \mathrm{mg} / \mathrm{dl}$ en condiciones normales), la HPT es liberada hacia la circulación y actúa en diferentes sitios. En el hueso la HPT se une al receptor PTH1R (parathyroid hormone-related peptide 1 receptor) en los osteoblastos, osteocitos y células osteoprogenitoras y favorece la movilización de $\mathrm{Ca}^{2+}$ y fosfato del hueso a través de la estimulación de la diferenciación de los osteoclastos. Cuando el receptor PTH1R se activa por la unión con la HPT, los osteoblastos inducen la expresión de ligando activador del receptor NF-KB (RANKL, receptor activator for nuclear factor $\mathrm{K} B$ ligand), que se une a RANK (activador del receptor del factor nuclear $\mathrm{kB}$ ) presente en los preosteoclastos, y promueve su diferenciación a osteoclastos activos para finalmente aumentar la resorción ósea. Los osteoblastos presentan receptores para la HPT que al ser activados sintetizan factores activadores de los osteoclastos, los cuales reabsorben hueso y se libera $\mathrm{Ca}^{2+}$ a la sangre $^{42}$. Cuando por alguna razón hay exceso de secreción de HPT, esta estimula la resorción ósea, que resulta en osteopenia y osteoporosis, y los huesos se vuelven más propensos a fracturas. En el riñón, la HPT actúa regulando tres procesos relacionados con el metabolismo mineral: 1) bloqueando la resorción del fosfato; 2 ) aumentando la resorción de $\mathrm{Ca}^{2+}$, y 3) favoreciendo la síntesis de vitamina $\mathrm{D}$ activa $(1,25-(\mathrm{OH}) 2 \mathrm{D})^{43}$. La 1,25-(OH)2D incrementa la osteoclastogénesis al inhibir la expresión de la osteoprotegerina (OPG, to protect bone), también conocida como «factor de inhibición de la osteoclastogénesis» (OCIF o TNFRSF11B), que es un receptor soluble del osteoblasto que compite con RANK por la unión de RANKL. De esta forma, la HPT y la 1,25-(OH)2D aumentan la calcemia al incrementar los osteoclastos activos en el hueso ${ }^{44}$. La resorción del $\mathrm{Ca}^{2+}$ en el riñón ocurre aproximadamente alrededor del $65 \%$ en el túbulo contorneado proximal y el $15 \%$ en la parte ascendente del asa de Henle, mediante transporte pasivo independiente de la HPT. El ajuste fino de la excreción de $\mathrm{Ca}^{2+}$ se lleva a cabo principalmente en el túbulo distal por transporte activo dependiente de la HPT, donde se reabsorbe el $20 \%$ del $\mathrm{Ca}^{2+}$ filtrado ${ }^{43}$. La otra forma en que la HPT actúa para aumentar los niveles sanguíneos de $\mathrm{Ca}^{2+}$ es por medio de su influencia en el epitelio intestinal. En este sitio, la absorción de $\mathrm{Ca}^{2+}$ involucra dos procesos: uno pasivo, que se efectúa primordialmente en el yeyuno e íleon, y el otro por transporte activo en el duodeno y la parte proximal del yeyuno, el cual es responsable de la absorción del $90 \%$ del $\mathrm{Ca}^{2+43}$. Debido a que la HPT aumenta la formación de 1,25-(OH)2D, el incremento en las concentraciones de esta última aumenta la absorción intestinal de $\mathrm{Ca}^{2+}$ (Fig. 6).

\section{CONCLUSIÓN}

Las glándulas paratiroides están presentes en todos los animales vertebrados superiores a los peces, y derivan de las bolsas faríngeas. Estudios recientes indican que las glándulas paratiroides en tetrápodos y las branquias de los peces son estructuras relacionadas evolutivamente, y que las glándulas paratiroides pueden surgir como resultado de la transformación de las branquias durante la evolución de los tetrápodos. Estas glándulas fueron estructuras enigmáticas por largo tiempo hasta que Owen las descubrió por primera vez, Sandström precisó su histología y les dio su nombre; pero fueron Gley, Erdheim y Albright quienes verdaderamente reconocieron el funcionamiento paratiroideo. Bien dice Ragnar A. Granit (premio Nobel en Medicina 1967) que el verdadero descubridor no es aquel que ve un fenómeno por primera vez, sino el que lo entiende y lo hace entendible a los demás. Es de mayor importancia para el médico general, y para el endocrinólogo y patólogo en particular, que tengan una comprensión completa de las glándulas paratiroides para el adecuado manejo del paciente con problemas paratiroideos.

\section{FINANCIAMIENTO}

La presente investigación no ha recibido ninguna beca específica de agencias de los sectores público, comercial, o sin ánimo de lucro. 


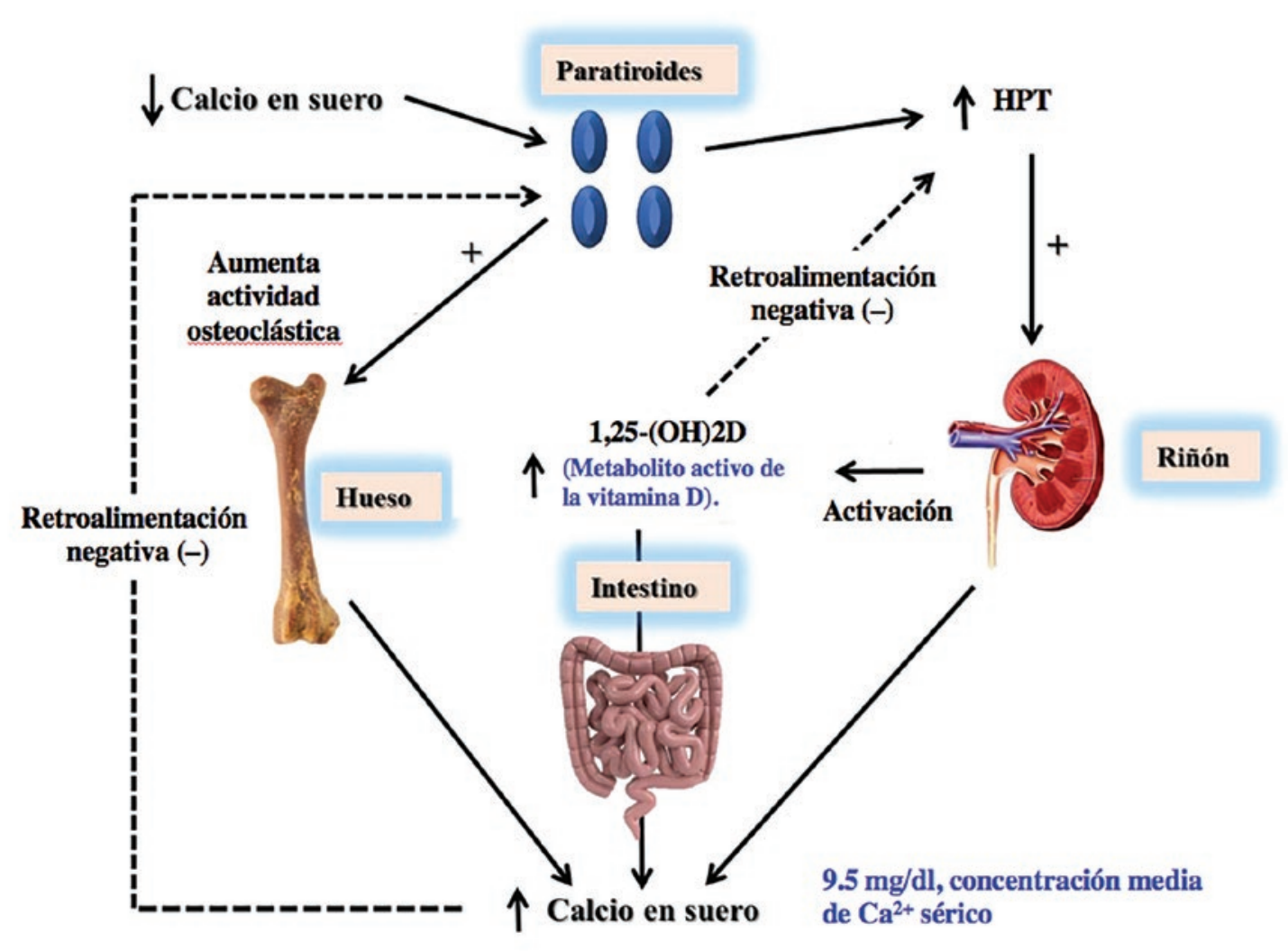

Figura 6. Esquema que demuestra la función de la hormona paratiroidea en la homeostasis del calcio. Las glándulas paratiroides responden a la baja concentración de calcio sérico secretando HPT, lo que estimula la resorción ósea por los osteoclastos, la resorción tubular renal de calcio y la síntesis de vitamina D activa (1,25-(OH)2D). La principal función endocrina de la 1,25-(OH)2D es el incremento de la absorción intestinal de $\mathrm{Ca}^{2+}$ y favorecer la movilización de $\mathrm{Ca}^{2+}$ del hueso y estimular la resorción de $\mathrm{Ca}^{2+}$ en el riñón. Todos estos mecanismos restauran la concentración de calcio en la circulación.

\section{CONFLICTO DE INTERESES}

Los autores declaran no tener conflicto de intereses.

\section{RESPONSABILIDADES ÉTICAS}

Protección de personas y animales. Los autores declaran que para esta investigación no se han realizado experimentos en seres humanos ni en animales.

Confidencialidad de los datos. Los autores declaran que han seguido los protocolos de su centro de trabajo sobre la publicación de datos de pacientes.
Derecho a la privacidad y consentimiento informado. Los autores declaran que en este artículo no aparecen datos de pacientes.

\section{BIBLIOGRAFÍA}

1. Chen H, Senda T, Emura S, Kubo K-y. An update on the structure of the parathyroid gland. Open Anatomy Journal. 2013;5:1-9.

2. Goltzman D. Physiology of parathyroid hormone. Endocrinol Metab Clin N Am. 2018;47:743-58.

3. Nordenström J, Marcus R. History of the parathyroid gland and their secretory product. Parathyroid hormone. En: Biliezikian J. The parathyroid gland. Basic and clinical concepts. 3rd ed. Amsterdam: Elsevier; 2015. pp. 1-17.

4. Kafetzis ID, Diamantopoulos A, Christakis I, Leoutsakos B. The history of the parathyroid glands. Hormones. 2011;10:80-4.

5. McAneny D, Beazley RM. The glands of Owen. Who was Owen? Surgery. 2016;159:7-10.

6. Carney JA. The glandulae parathyroideae of Ivar Sandström. Contributions from two continents. Am J Surg Pathol. 1996;20:1123-44. 
7. Dorairajan N, Pradeep PV. Vignette hyperparathyroidism: Glimpse into its history. Int Surg. 2014;99:528-33.

8. Udelsman R, Citino SB, Prasad M, Donovan PI, Fredholm DV. Parathyroid, thyroid and recurrent laryngeal nerve anatomy in an Indian rhinoceros (Rhinoceros unicornis). World J Surg. 2018;42:514-20.

9. Breimer $L$, Sourander. The discovery of the parathyroid glands in 1880: triumph and tragedy for Ivar Sandström. Bull Inst Hist Med. 1918:5:558-63.

10. Sandström IV. On a new gland in man and several mammals - glandulae parathyroideae. Upsala Läk Förenings Förh. 1879-880;15:441-71.

11. Kock W. Medicinska klassiker V Ivar Viktor Sandström. Svenska Läkartidningen. 1944;34:2073-82.

12. Gley E. Sur la toxicité des urines des chiens thyroidectomisés: contribution à l'étude des fonctions du corps thyroide. Comptes Rendus de la Société de Biologie. 1891;3:366-8.

13. Vermeulen AHM. The birth of endocrine pathology. How Erdheim misunderstood parathyroids. Virchows Arch. 2010;457:283-90.

14. Erdheim J. Beiträge zur pathologischen anatomie der menschlichen epithel-körperchen. Zeitschrift für Heilkunst. 1904;25:1-15.

15. Erdheim J. Ueber tetania parathyreopriva. Weiner Klinishe Wachenschrift. 1906;19:716-7.

16. Brand RA. Friedrich Daniel von Recklinghausen, MD (1833-1910) Clin Orthop Relat Res. 2011;469:1225-6.

17. Kalra S, Baruah MP, Sahay R, Sawhney K. The history of parathyroid endocrinology. Indian J Endocrinol Metab. 2013;17:320-2.

18. Eknoyan G. A history of the parathyroid glands. Am J Kidney Dis. 1995;26:801-7.

19. Noble RL. Memories of James Bertram Collip. Can Med Assoc J. 1965; 93:1356-64.

20. The Endocrine Society Staff. In Memoriam: Dr. Rosalyn Yalow, PhD. 19212011. Mol Endocrinol. 2012;26:713-4.

21. Kleeman CR, Levine BS, Felsenfeld AF. Fuller Albright: The consummate clinical investigator. Clin J Am Soc Nephrol. 2009;4:1541-6.

22. Peissig K, Condie BG, Manley NR. Embryology of the parathyroid glands. Endocrinol Metab Clin North Am. 2018;47:733-42.

23. Cinque L, Pugliese F, Salcuni AS, Scillitani A, Guarnieri V. Molecular pathogenesis of parathyroid tumours. Best Pract Res Clin Endocrinol Metab. 2018;32:891-908.

24. Scharpf J, Kyriazidis N, Kamani D, Randolph G. Anatomy and embryology of the parathyroid gland. Oper Tech Otolayngol Head Neck Surg. 2016:27:117-21.

25. Noussios G, Anagnostis P, Natsis K. Ectopic parathyroid glands and their anatomical, clinical and surgical implications. Exp Clin Endocrinol Diabetes. 2012:120:604-10.

26. Van der Walt J. Pathology of the parathyroid glands. Diag Histopathol. 2012;18:221-33.

27. Roth SI, Sadow PM, Johanson NB, Abu-Jawdaeh G. Paratyroid. En: Mills SE. Histology for pathologists. 4th ed. Philadelphia: Lippicot-Williams \& Wilkins; 2012. pp.1209-1230
28. Brown MB, Limaiem F. Histology, parathyroid gland [Internet]. Treasure Island (FL): StatPearls Publishing [fecha última actualización: 20 de septiembre de 2019]. Disponible en: https://www.ncbi.nlm.nih.gov/books/ NBK546596/

29. Elliott D, Monroe D, Perrier N. Parathyroid histopathology: is it of any value today? J Am Coll Surg. 2006;203:758-65.

30. Yao K, Singer FR, Roth SI, Sassoon A, Ye C, Giuliano AE. Weight of normal parathyroid glands in patients with parathyroid adenomas. J Clin Endocrinol Metab. 2004:89:3208-13.

31. Saffros RO, Rhatigan RM, Urgulu S. The normal parathyroid and the borderline with early hyperplasia: a light microscopic study. Histopathology. 1984;8:407-22.

32. Anton RC, Wheeler TM. Frozen section of thyroid and parathyroid specimens. Arch Pathol Lab Med. 2005;129:1575-84.

33. Trier JS. The fine structure of the parathyroid gland. J Biophysic Biochem Cytol. 1958;4:13-21

34. Zhang N, Koo HM, Weinreich M, Williams BO, Teh BT. Parafibromin inhibits cancer cell growth and causes G1 phase arrest. Biochem Biophys Res Commun. 2006;350:17-24.

35. Hossy Mohammed K, Siddiqui MT, Willis BC, Zaharieva Tsvetkova D, Mohamed A, Patel S, et al. Parafibromin, APC, and MIB-1 are useful markers for distinguishing parathyroid carcinomas from adenomas. Appl Immunohistochem Mol Morphol. 2017;25:731-5.

36. DeLellis RA, Arnold A, Bilezikian JP, Eng C, Larsson C, Lloyd RV, et al. Parathyroid carcinoma. En: Lloyd RV. WHO Classification of tumors of endocrine organs. 4th ed. Lyon: IARC; 2017. pp. 147-152

37. Nonaka D. Study of parathyroid transcription factor $\mathrm{Gcm} 2$ expression in parathyroid lesions. Am J Surg Pathol. 2011;35:145-51.

38. Higgins SE, Barletta JA. Applications of immunohistochemistry to endocrine pathology. Adv Anat Pathol. 2018;25:413-29.

39. Erickson LA, Mete O. Immunohistochemistry in diagnostic parathyroid pathology. Endocr Pathol. 2018;29:113-29.

40. Shakeel S, Mubarak M. Proliferative lesions of parathyroid glands: An update for practicing pathologists. J Coll Physicians Surg Pak. 2016; 26:51-9.

41. Khan M, Sharma S. Physiology, parathyroid hormone (PTH) [Internet]. Treasure Island (FL): StatPearls Publishing; 2019 [fecha de última actualización: 25 de abril de 2019]. Disponible en: https://www.ncbi.nlm.nih. gov/books/NBK499940/

42. Ávila E, Barrera D, Díaz L. Acciones calciotrópicas de la hormona paratiroidea y del sistema endocrino de la vitamina D. Rev Inv Clín. 2007;59:306-17.

43. Conigrave AD. The calcium-sensing receptor and the parathyroid: Past, present, future. Front Physiol. 2016;15:1-13.

44. Ferrer Cañabate J, Tovar I, Martínez P. Osteoprotegerina y sistema RANKL/RANK: ¿el futuro del metabolismo óseo? An Med Interna (Madrid). 2002;19:385-8. 